\title{
Hacia una teoría inductiva de la Literatura Latinoamericana
}

\author{
RAUL BUENO
}

A Antonio y Nelson, amigos y maestros de siempre, con quienes he discutido parte de estas ideas.

\section{O.}

Estuve no hace mucho en un foro en que se terminó discutiendo la aridez y el fracaso de las teorías literarias, en general, y de los proyectos de teoría de la literaturas latinoamericanas, en particular ${ }^{1}$.

Incluso las voces más temperadas de este simposio hablaban deceptivamente de tales proyectos, aunque dejaban como saldo positivo de este siglo de estudios literarios latinoamericanos el ejercicio fructífero (hay que destacarlo) de una crítica persistente y original. Frente a actitudes ad anti-teóricias como ésa, que se repiten ya con alguna frecuencia, quiero afirmar positivamente la existencia de la teoría de la literatura latinoamericana. Quiero señalar que el hecho de que ciertos proyectos por constituirla hayan quedado aparentemente estancos no da pie para proclamar su inexistencia, aunque sea de modo tentativo o estratégico ${ }^{2}$. En lo que sigue intentaré argumentar dicha existencia en dos niveles básicos: en su dependencia necesaria de la literatura a la que busca servir; y en el modo acumulativo y polémico de su constitución.

${ }^{1}$ Congreso sobre "Estado Actual de los Estudios Literarios Latinoamericanistas". Universidad de Granada, 27-31 de enero de 1992 y funciones de la teoría.

${ }^{2}$ Que tendería supuestamente, a alentar su verdadera constitución. 


\section{De la inducción}

Las teorías de la literatura no se "inventan". Quiero decir que no son el producto de una racionalidad operando en el vacío. Parten de una materialidad objetual; y, más aún, se desprenden de los objetos reales a los que describen conceptualmente. Tomemos el caso de Aristóteles: él no se propuso inventar un sistema teórico, sino que lo extrajo de una literatura que él conocía bien y que, por ende, describió con exhaustividad, en sus variedades fenoménicas y en sus rasgos distintivos generales, de estructura y funcionamiento. Hay que decirlo mejor: indujo (y remarco el término) la teoría de la literatura griega antigua, que no era (no, pretendía ser, pero resulto lo que fue, y, en gran medida, aún lo es) una teoría literaria universal. Las teorías literarias las producen, en verdad, las culturas en que aquellas se desarrollan; pero de una manera implícita, pues lo que de verdad producen es la literatura que las contiene. Vladimir Propp, lo he dicho en otra oportunidad, no inventó la teoría del relato, sino que describió exhaustivamente las formas básicas del cuento maravilloso ruso. Es decir extrajo y abstrajo las situaciones comunes y constantes de su corpus, y formalizó un modelo canónico para todos ellos. A partir de este modelo se producen después todos los demás que, en relaciones complementarias o no, constituyen ese sector de la teoría literaria general denominado teoríade relate Letras

En el caso que nos concierne, debo decir que la literatura latinoamericana (sus sistemas literarios) contiene(n) su teoría. Y todas sus posibles teorías, a condición de que estén honestamente construidas. Es labor nuestra, de sus críticos y teóricos, el expresarla, el hacerla explícita, el inducirla ${ }^{3}$. Si no tenemos suficiente material para hablar de la teoría de la literatura latinoamericana como un conjunto orgánico ${ }^{4}$, depositado en un específico texto metalingüístico, no es porque esa

${ }^{3}$ En el ensayo "Sentido y requerimientos de una teoría de las literaturas latinoamericanas" incluido en mi libro Escribir en Hispanoamérica: ensayos sobre teoría y critica literarias (Lima/Pittsburgh: Latinoamericana Editores, 1991), hablo de proceder inductivamente, de desprender, a partir del ejercicio crítico e histórico de nuestras literaturas, las categorías y modelos que van a integrar una teoría de la literatura latinoamericana (pp. 105s).

${ }^{4}$ Con la organicidad relativa que explicaré en la segunda sección de este trabajo. 
teoría no exista, sino porque no se le ha inducido suficientemente, primero; y, por consiguiente, no se la ha hecho explícita en toda su extensión.

Nuestra tarea de estudiosos de la literatura consiste, entonces, en hacer visibles los sistemas teóricos del conjunto llamado literatura latinoamericana. En otras palabras, consiste en extraer de los fenómenos y sistemas literarios latinoamericanos los dispositivos conceptuales y modelos que mejor los representan, describen y explican. En esta tarea, como veremos luego, caben representaciones de distinta generalidad y nivel, desde los dispositivos que formalizan un corpus bien ceñido a una especialidad, como sería la novela de dictadores, hasta los más extensos, que quisieran abarcar toda la complejidad fenoménica de campos como la literatura brasileña, la hispanoamericana, o la caribeña. Y caben no sólo los modelos de vocación netamente teórica, a los que designaríamos de teoría "pura", sino aquellos que se orientan al servicio del a crítica ola historia literarias.

El esquema que sigue intenta sistematizar gran parte de lo hasta aquí dicho, a la vez que representar aspectos que he adelantado en otras oportunidades y que tienen que ver con las relaciones entre la literatura latinoamericana y las distintas disciplinas de los literario. Como todo esquemail suliargunentolese apoya sen índices y en otros signos de espacialidad, rgue nosiahorran uña sexplicación demorada y verbosa:

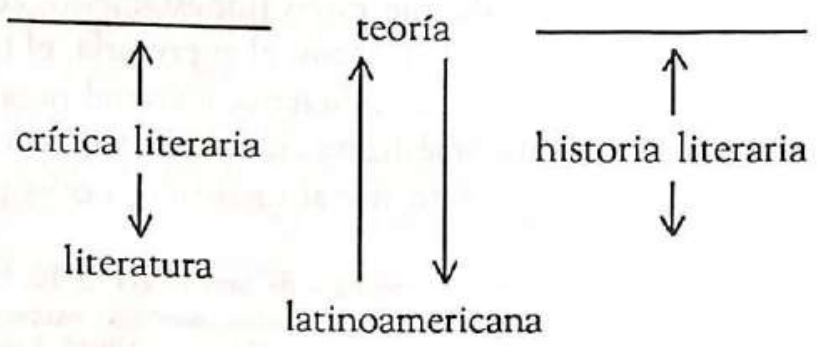

2. De la diversidad de campo

Nadie ha dicho que la teoría de una literatura tenga que ser necesariamente un cuerpo de reflexiones completo, acabado e indis- 
cutible . Las teorías se construyen para proponer ciertos inteligibles, de distinto alcance y nivel, de los conjuntos de objetos y fenómenos empíricos de los que se hacen cargo. Por lo tanto, las teorías están sujetas a discusión y revisión de manera permanente. Una teoría literaria, por otro lado, no necesita ser una, ni la teoría. La historia cultural europea nos muestra que la teoría literaria es un actividad continua y variopinta, de adiciones, rectificaciones, modificaciones y polémicas; y que más que un sistema conceptual uniforme, totalizador y coherente, es un campo de reflexiones teóricas, relativamente definido y sostenido por una base epistemológica más o menos cambiante.

En ese campo caben distintas teorías, determinadas no sólo por la extensión, la clase y el nivel del corpus fenoménico sobre el que se constituyen, sino también por la índole del objeto (objetivo) teórico que las articula. En el campo teórico hasta ahora más visible, el de las literaturas europeas, resulta que en lugar de una teoría literaria existen ahí muchas teorías, de diferente vigencia, extensión, nivel y proyecto, como pudo verse ya en en viejo ( $y$ en cierto modo todavía vigente) panorama teórico de R. Wellek y A. Warren ${ }^{6}$. Ejemplo destacado de un renglón de esa diversidad to constituye la llamada teoría del relato. Este, como se sabe, no depende necesariamente de la teoría de los géneros literarios, puesto que en gran medida, trasciende lo literario.

Ella está, en realidad integrada por varios sistemas teóricos, algunos de ellos tan incompatibles y aun opuestos, como el triádico de Bremond y el conjuntivo/disyuntivo (o binario) de Greimas; o tan vecinos y al mismo tiempo tan ajenos los unos de los otros, como la teoría del narrador (de las voces del relato, es decir la verdadera narralogía) y la estructura actancial. No hay, pues, acuerdo visible entre esas teorías; ni es impositivo el que lo haya.

Lo dicho deja en claro que no ha de esperarse de la teoría literaria general, ni, por lo tanto, de las teorías literarias latinoamericanas, la coherencia del producto unitario y acabado, porque constituye, insisto, un campo de actividades cognositivas y no un organismo con-

${ }^{5}$ Se aspira a ello, como, en otro ámbito, se aspira a las utopías; pero ello no significa que tal plenitud y coherencia sean algo de veras alcanzable. Son, en cierto modo, el desideratum que impulsa el cambio incesante del conjuento teórico.

${ }^{6}$ René Wellek y Austin Warren, Teoría literaria. Madrid, Gredos, 1953. 
ceptual. Un campo que se moviliza constantemente, produciendo la incesante agitación de modelos y conceptos que todos conocemos. Ha de esperarse de la teoría, sí, una variedad y una riqueza crecientes, un diálogo y una polémica interiores constantes, porque en su amplitud, diversidad y espesor está la posibilidad de un ajuste cognositivo más cabal respecto a los objetos y fenómenos que se propone describir.

En el caso de América Latina, tal efervescencia progresiva y enriquecedora del campo ya existe. Es cierto que no en el grado en que se quisiera, ni con la celeridad que la complejidad fenoménica requiere; pero ahí está. Y puesto que está, no podemos menos afirmar la existencia de la teoría de las literaturas latinoamericanas en tanto que campo, repito, o lugar de múltiples actividades teórico-literarias. El carácter fragmentario o no, tentativo o no, superado o no de sus distintos dispositivos no niega la presencia de una polifonía conceptual que, por acuerdo o simple coincidencia, de pronto produce sus acordes. No se necesita, a estas alturas, documentar con nombres y proyectos que todos conocemos esa variedad creciente de nuestro campo. mente.

Simplemente hagamos un esfuerzo por congregarlo aquí mental-

Si a lo anteribe se agregan las posibilidades descriptivas y de formalización que 'eomerprendé la compleją fenömenología de nuestras literaturas, entonces tenemos, como se ha visto, otro argumento para abundar en la existencia de la teoría que nos ocupa. Esta vez se trata de una afirmación basada en la inmanencia: hay teoría (conceptos, categorías, modelos, etc.) a desprenderse de esas presencias fenoménicas. Hay teoría implicita, propicia a su demostración y abierta a su concreción discursiva, a su explicitación franca y progresiva. Tal es nuestro reto de estudiosos; nuestra difícil pero hermosa tarea de desvelamiento.

\section{Coda celebrante}

A la luz de todo lo anterior, no podemos decir, como se dice últimamente en algunos foros, que el proyecto teórico de Roberto Fernández Retamar haya fracasado, primero, porque no es -nunca pretendió serlo- una teoría de la literatura latinoamericana, sino una 
discusión epistemológica por constituirla: ahí el autor nos hablaba de por qué y cómo había que desarrollar un pensamiento teórico sobre el particular y, en cierto modo, del método que era necesario implementar para desarrollarlo. $Y$, segundo, porque en los años transcurridos desde la aparición de ese sustento epistemológico, muchos son los trabajos que le han hecho referencia seria y constructiva, y que han basado sus criterios, cuando no partes de sus estrategias descriptivas, en los supuestos constitucionales allí esbozados por Fernández Retamar.

En ese sentido, hay que decir que el proyecto en cuestión ha sido y es, por muchas razones, uno de los más provechosos de la historia de la cultura hispano/latinoamericana. La mayor de esas razones es, a $\mathrm{mi}$ modo ver, su muy cumplido papel de promotor, cuestionador y agitador de consciencias críticas y teóricas.

(Hanover, N.H., junio de 1992)

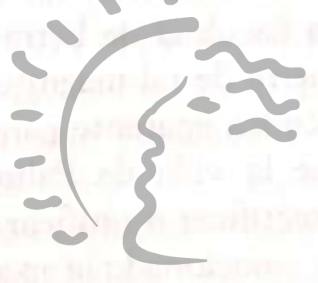

\section{Biblioteca de Letras "Jorge Puccinelli Converso»}

